\title{
The role of physical therapy and rehabilitation after lumbar fusion surgery for degenerative disease: a systematic review
}

\author{
Marcella Madera, MD, ${ }^{1}$ Jeremy Brady, DPT, ${ }^{2}$ Sylvia Deily, DC, ${ }^{2}$ Trent McGinty, DPT, ${ }^{2}$ \\ Lee Moroz, MD, ${ }^{3}$ Devender Singh, PhD, ${ }^{4}$ George Tipton, MD, ${ }^{5}$ and Eeric Truumees, MD, ${ }^{1}$ \\ for the Seton Spine Rehabilitation Study Group \\ ${ }^{1}$ Department of Surgery and Perioperative Care, The University of Texas Dell Medical School; ${ }^{2}$ Rehabilitation Service and \\ ${ }^{5}$ Orthopaedic Spine Surgery, Seton Spine \& Rehabilitation; and ${ }^{3}$ Physical Medicine \& Rehabilitation and ${ }^{4}$ Research, Seton Spine \\ \& Scoliosis Center, Austin, Texas
}

OBJECTIVE The purpose of this study was to provide a systematic and comprehensive review of the existing literature regarding postfusion rehabilitation.

METHODS Using the Preferred Reporting Items for Systematic Reviews and Meta-Analyses (PRISMA) guidelines, the authors conducted an exhaustive review of multiple electronic databases. Potential articles were screened using inclusion/exclusion criteria. Two authors independently analyzed these studies using predefined data fields, including study quality indicators such as level of evidence and availability of accepted patient-reported outcomes measures. These findings were synthesized in a narrative format. A third author resolved disagreements regarding the inclusion of a study.

RESULTS Twenty-one articles with I or II levels of evidence were included in the review. The authors divided the findings of the literature review into several groups: rehabilitation terminology, timing and duration of postfusion rehabilitation, the need for rehabilitation relative to surgery-related morbidity, rehabilitation's relationship to outcomes, and cognitive and psychosocial aspects of postsurgical rehabilitation. Current evidence generally supports formal rehabilitation after lumbar fusion surgery. Starting physical therapy at the 12-week postoperative mark results in better outcomes at lower cost than an earlier, 6-week start. Where available, psychosocial support improves outcomes. However, a number of the questions could not be answered with high-grade evidence. In these cases, the authors used "best evidence available" to make recommendations. There are many cases in which different types of caregivers use clinical terminology differently. The data supporting an optimal protocol for postfusion rehabilitation remains elusive but, using the data available, the authors have crafted recommendations and a model protocol, which is currently undergoing prospective study.

CONCLUSIONS Rehabilitation has long been a common feature in the postoperative management of patients undergoing spinal fusion. Although caregivers from multiple disciplines agree that the majority of their patients will benefit from this effort, the supporting data remain sparse. In creating a model protocol for postlumbar fusion rehabilitation, the authors hope to share a starting point for future postoperative lumbar fusion rehabilitation research.

https://thejns.org/doi/abs/10.3171/2016.10.SPINE16627

KEY WORDS rehabilitation; physical therapy; lumbar fusion surgery; outcome; systematic review; PRISMA; degenerative

$\mathrm{L}$ UMBAR degenerative disease is nearly universal in the aging spine. Typically, associated symptoms may be successfully managed nonoperatively. In patients with continued pain and functional limitations despite appropriate conservative modalities, operative intervention is considered. In patients with degenerative spinal instability, such as scoliosis or spondylolisthesis, a fusion is often offered. The limitations of fusion procedures are well known and include the muscle dissection required to carry out the approach and the impact segmen-

ABBREVIATIONS CBT = cognitive behavioral therapy; $\mathrm{LOE}=$ level of evidence; $\mathrm{LOS}=$ length of stay; NASS = North American Spine Society; ODI = Oswestry Disability Index; ROM = range of motion.

SUBMITTED May 29, 2016. ACCEPTED October 20, 2016.

INCLUDE WHEN CITING Published online March 10, 2017; DOI: 10.3171/2016.10.SPINE16627. 
tal immobilization will have on overall spinal kinematics. Postoperatively, physical therapy and other rehabilitative modalities have been frequently used to improve patients' activity level, range of motion (ROM), and core strength.

Recently the costs of spine care have been questioned. Deyo and Mirza reported that, over a decade, there was a $629 \%$ increase in Medicare spending for epidural steroid injections, a $423 \%$ increase in spending for opiate medications for back pain, and a 307\% increase in the number of lumbar MRI studies ordered in Medicare patients. ${ }^{19}$ Cowan et al. studied the Nationwide Inpatient Sample from 1993 to 2001 and found that overall use of lumbar fusion increased by $356 \%$ in that time frame. ${ }^{17}$ Kepler et al. studied the American Orthopedic Surgery database from 1999 to 2011 and found that the number of fusion procedures doubled during that period. ${ }^{36}$

Coordinated, multidisciplinary care using evidencebased guidelines has been suggested as a way to deliver the best outcomes while curbing costs..$^{58}$ In the course of our own multidisciplinary group's meetings to address quality and costs of spine care in our patient population, we realized that common terms concerning postoperative rehabilitation carried different meanings for the specialists involved. We also noted a wide divergence among practitioners in the rates of utilization of physical therapy and other rehabilitative services, the modalities requested, and the timing of such treatments relative to surgery. As we sought to coordinate care, we wanted to establish an evidence base for our recommended rehabilitation regimens.

Rehabilitation as a primary treatment for back pain (i.e., without surgery) has been shown to be effective in several randomized controlled trials for patients with degenerative disc disease and back pain, with success rates as high as $60 \%{ }^{10-13,24,44,45,48,49}$ Several of these seminal papers compared outcomes of rehabilitation versus fusion surgery for degenerative disease. ${ }^{13,25,27,35,44,48,69}$

There are far fewer studies examining the role of postoperative rehabilitation after lumbar fusion. In the postoperative setting, much of the rehabilitation literature focuses on postdiscectomy patients. ${ }^{9,32,37}$ The aim of this study was to conduct a systematic and comprehensive review of the existing literature regarding postfusion rehabilitation.

\section{Methods Study Design}

A systematic review was conducted in accordance to the Preferred Reporting Items for Systematic Reviews and Meta-Analyses (PRISMA) Statement for Reporting Systematic Reviews..$^{50}$ The study was exempt from review of the institutional review board.

\section{Search Criteria}

We conducted a comprehensive computerized literature search through multiple electronic databases without date limits up until November 2014 by using combinations of key search terms. MEDLINE was searched using PubMed and OvidSP search engines; Cochrane Controlled Trials Register and EMBASE were also searched for any potential studies. The OvidSP included the following: Ovid MEDLINE without revisions (1996-Nov 2014); Books @Ovid (25th Nov, 2014); Ovid MEDLINE (1946-Nov 2014); Ovid MEDLINE without revisions (1946-1995); Ovid MEDLINE In-Process \& Other NonIndexed Citations and Ovid MEDLINE (1946-present); Ovid MEDLINE In Process \& Other Non-Indexed Citations (3rd Nov, 2014); Ovid OLDMEDLINE (1946-1965); Seton Healthcare Family Journals @ Ovid; and Journals @Ovid Full Text (3rd Nov, 2014). The search strategy used for PubMed is shown in the Appendix (see onlineonly content). Other databases followed the same search strategy.

\section{Search Terms}

Our search strategy focused on the combinations of the following key terms: "Lumbar fusion," "Spinal fusion," "Physical therapy," "Rehabilitation," "Spinal surgery," "Brace," "Posture correction," "Patient education," "Joint mobilization," "Soft tissue manipulation," "Therapeutic exercise," "Extensor strength," "Muscle endurance," "Mobility," "Quality of life (QOL)," and "Cognitive behavioral therapy (CBT)."

\section{Inclusion and Exclusion Criteria}

Articles for potential selection were screened using inclusion and exclusion criteria. Inclusion criteria include studies published in peer-reviewed journals in English or translated into English and studies with postoperative rehabilitation after spinal fusion for degenerative spinal conditions in adults in which a clear description of the rehabilitative strategy was provided.

Studies with the following criteria were excluded: 1) non-English; 2) no spinal fusion surgery; 3) no postoperative rehabilitation after spinal surgery; 4) no clear description of postoperative rehabilitative strategy; 5) basic science studies; 6) not a full-text article (editorials or letters); 6) insufficient sample size; 7) no well-defined outcome measures used; 8) papers that could not be found; or 9) didn't meet the minimum level of evidence (LOE) (i.e., I or II).

\section{Data Extraction}

Two research librarians and 1 of the authors (D.S.) performed the electronic database search. Two authors (E.T. and T.M.) independently reviewed these studies to be potentially included in the systematic review by using predefined data fields, including study quality indicators such as LOE and availability of accepted patient-reported outcomes measures. These findings were synthesized in a narrative format. Disagreements on the inclusion of a study were resolved by a third author (M.M.). In addition, we also performed manual searches of review bibliographies and reference lists of primary studies not captured by the electronic searches. To further avoid missing studies not referenced in our original papers' bibliographies or our literature searches, we sought additional recommendations from prominent researchers in the field. Additional full-text references were then obtained and analyzed for inclusion. 


\section{Results}

Our initial search resulted in 1850 articles. Of these, we excluded those identified as duplicate articles, editorials, letters, or basic science studies, and identified 210 full-text articles. With detailed analysis, we excluded 61 full-text articles (13 non-English; 14 could not be found; 21 with no well-defined outcome measures, and 13 with insufficient patient samples). A total of 149 full-text articles were found to be relevant for the systematic review. Of these 149 articles, 123 did not meet the minimum LOE (i.e., II) and were excluded from the review. The remaining 26 articles with I or II LOEs were included in the review. On further review, 5 of these articles were found to be irrelevant and were excluded from the current study (Fig. 1). Articles included in the final review are listed with their LOEs in Table 1.

We divided the findings of the literature review into several groups: general rehabilitation terminology, timing and duration of postfusion rehabilitation, the need for rehabilitation relative to surgery-related morbidity, rehabilitation's relationship to outcomes, and cognitive and psychosocial aspects of postsurgical rehabilitation.

We encountered a variety of terms that carried differ- ent meanings for different care provider classes. To proceed further, therefore, we sought to establish some common definitions for the components of rehabilitation.

To establish a standardized postlumbar fusion rehabilitation protocol, we next queried the literature for optimal timing and duration of postoperative rehabilitation. Other primary questions included the following: how does the extent of surgery relate to postoperative rehabilitation needs, what is the impact of postoperative rehabilitation on treatment outcomes, and how do psychosocial diagnoses or support systems impact these outcomes?

We used standard North American Spine Society (NASS) grades of recommendation for summaries or review studies, as shown in Table 2. ${ }^{21}$ These findings are summarized in Table 3.

\section{Definitions}

Only a few papers offered specific and detailed rehabilitation protocols. In that there were insufficient data to assess individual elements of these protocols, they were studied "as one." That said, most authors favored specific rehabilitation techniques as part of a multidisciplinary approach. For instance, Tarnanen et al. emphasize the

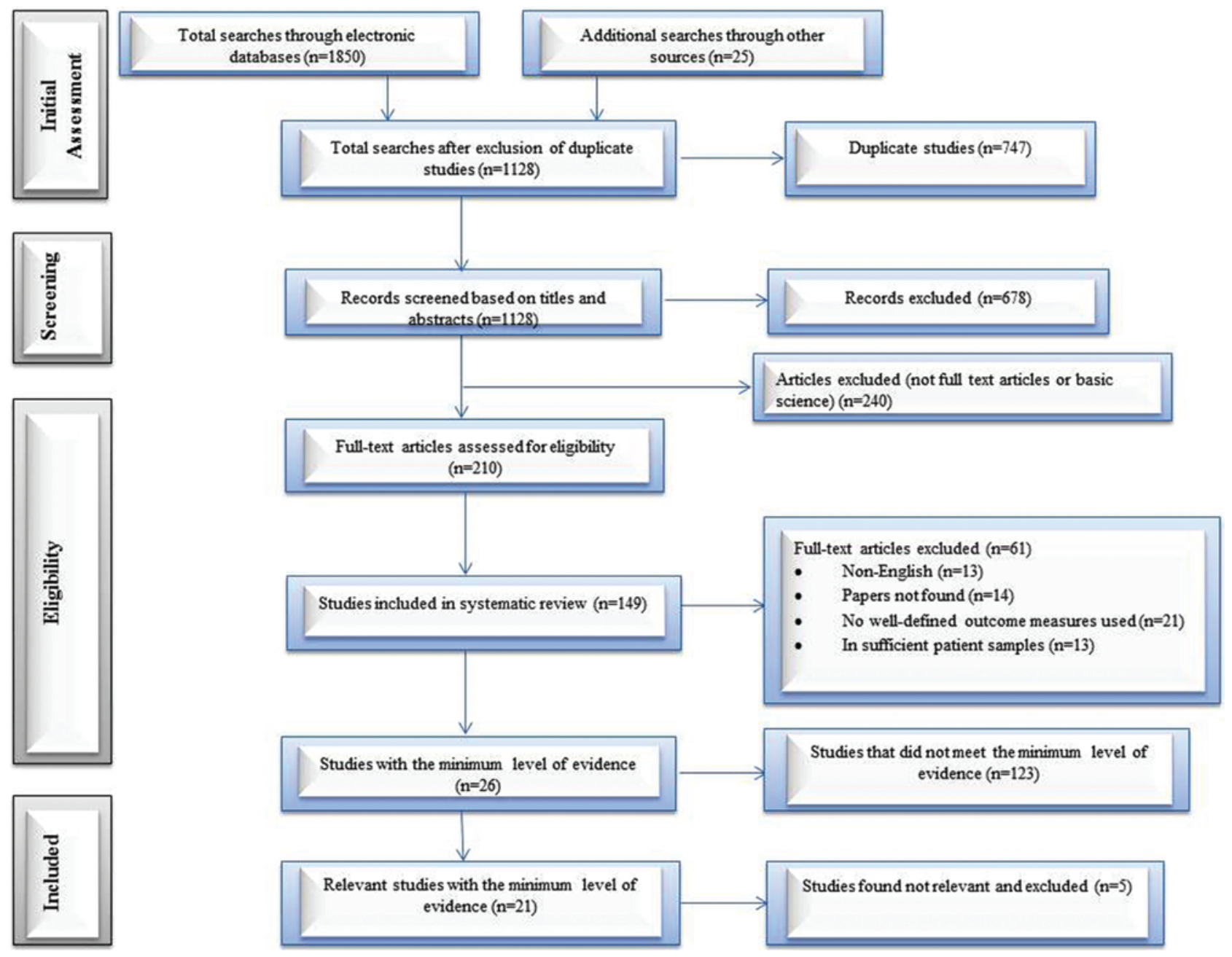

FIG. 1. Flow chart of systematic review. Figure is available in color online only. 
TABLE 1. Articles included in the final review, with LOEs

\begin{tabular}{cl}
\hline LOE & \multicolumn{1}{c}{ Relevant Papers } \\
\hline II & Biering-Sørensen, 1984 \\
\hline II & Moffett et al., 1999 \\
\hline II & Mannion et al., 2001 \\
\hline I & Scrimshaw \& Maher, 2001 \\
\hline II & Christensen et al., 2003 \\
\hline II & Brox et al., 2003 \\
\hline II & Fairbank et al., 2005 \\
\hline I & Keller et al., 2004 \\
\hline II & Häkkinen et al., 2005 \\
\hline I & Rosenberger et al., 2005 \\
\hline II & Brox et al., 2006 \\
\hline II & Mannion et al., 2007 \\
\hline I & Andersen et al., 2009 \\
\hline I & Nielsen et al., 2010 \\
\hline I & Brox et al., 2010 \\
\hline II & Froholdt et al., 2011 \\
\hline I & Froholdt et al., 2012 \\
\hline II & Oestergaard et al., 2012 \\
\hline II & Willems, 2013 \\
\hline & Oestergaard et al., 201356 \\
\hline & Oestergaard et al., 201354 \\
\hline
\end{tabular}

importance of maintaining neutral spine position while strengthening core muscles,${ }^{64}$ while Oestergaard et al. ${ }^{54-56}$ model their rehabilitation after Christensen et al.'s biopsychosocial "Back Café" model. ${ }^{16}$

In most of the studies analyzed, postfusion rehabilitation was poorly defined. Where physical therapy is mentioned, it often falls into several categories: generalized cardiovascular exercise (including aerobic work on bicycle or walking), generalized strength training, motor control/ stability training, soft-tissue and nerve mobility, joint mobility/stretching, patient education, and psychosocial interventions. Literature support for passive modalities such as ultrasound, electrical stimulation, thermal agents, and other modalities has been decreasing over the past 2 decades. ${ }^{4,66}$

Although descriptions of the components of postoperative rehabilitation programs were rarely offered, a few common themes emerged. Most authors recommend customizing a program based on individual patient needs. Many authors also emphasize the identification and treatment of any psychosocial barriers to recovery. The most common components of these programs are defined below.

\section{Specific Components of Postfusion Rehabilitation}

\section{Cardiovascular Exercise}

Generalized, aerobic exercise is often a major element of postoperative rehabilitation. Brennan and colleagues suggest that increasing aerobic capacity positively impacts
TABLE 2. Grades of recommendation for summaries or review studies

\begin{tabular}{cc}
\hline $\begin{array}{c}\text { NASS Grade } \\
\text { for LOE }\end{array}$ & Details \\
\hline A & $\begin{array}{c}\text { Good evidence (Level I studies w/ consistent findings) } \\
\text { for or against recommending intervention }\end{array}$ \\
\hline B & $\begin{array}{r}\text { Fair evidence (Level II or Ill studies w/ consistent find- } \\
\text { ings) for or against recommending intervention }\end{array}$ \\
\hline C & $\begin{array}{c}\text { Poor-quality evidence (Level IV or V studies) for or } \\
\text { against recommending intervention }\end{array}$ \\
\hline I & $\begin{array}{c}\text { Insufficient or conflicting evidence that does not allow } \\
\text { a recommendation for or against intervention }\end{array}$ \\
\hline
\end{tabular}

Evidence for or against recommending an intervention is listed as $A=$ good evidence (Level I study with a consistent finding); $B=$ fair evidence (Level II or III study with a consistent finding); C = poor-quality evidence (Level IV or V study); I = inconsistent or conflicting evidence that does not warrant recommending for or against an intervention. [https://www.spine.org/Research ClinicalCare/Research/GradesofRecommendation.aspx]

long-term health without increasing back pain symptoms after lumbar surgery. ${ }^{9}$ A number of other studies support the short-term benefits of generalized exercise in terms of decreased pain and increased function. ${ }^{2,4,32,48,63}$ However, such aerobic exercise therapy is a primary focus in only a few of the reviewed studies, and where it is defined, those definitions vary greatly.

An emphasis on cardiovascular exercise, typically walking, is common in rehabilitation for lumbar surgeries, both preoperatively and postoperatively. Evidence suggests that regular cardiovascular exercise performed preoperatively decreases length of stay (LOS) and improves Roland-Morris scores postoperatively..$^{52} \mathrm{~A}$ recumbent bike can be useful to increase cardiovascular health preoperatively, if a patient's walking tolerance is limited by his/ her symptoms. Aquatic exercise may also be effective in increasing cardiovascular health, and has the benefits of buoyant lumbar traction as well as lower-extremity compression to fight swelling. However, it lacks weight bearing, which is an important component of bone health and functional strengthening of the extensor musculature against gravity.

With modern, rigid spinal instrumentation, patients undergoing fusion for degenerative disease are believed to leave the operating room with adequate stability for immediate mobilization. Early mobility (transfer training and supervised gait training) in the acute care setting has been suggested to reduce adverse events, pain, and LOS.

Upon discharge, there is an expectation of gradual increase in distance and frequency of walking, as symptoms allow. We recommend that care providers include cardiovascular exercise in both pre- and postoperative fusion rehabilitation programs (Table 3).

\section{Soft-Tissue Mobilization}

Massage therapy is often used postoperatively to reduce inflammation, decrease pain, and facilitate patient recovery. Pressure and touch are thought to encourage these changes by restoring lymphatic drainage, improving 
TABLE 3. The NASS strategy for grading of evidence and recommendations for various components of postfusion rehabilitation

\begin{tabular}{|c|c|c|c|}
\hline $\begin{array}{l}\text { Components of } \\
\text { Rehabilitation }\end{array}$ & $\begin{array}{l}\text { Clinical } \\
\text { Question }\end{array}$ & $\begin{array}{l}\text { Guideline/ } \\
\text { Recommendation }\end{array}$ & $\begin{array}{l}\text { NASS } \\
\text { Grade }\end{array}$ \\
\hline $\begin{array}{l}\text { Cardiovascular } \\
\text { exercise }\end{array}$ & $\begin{array}{l}\text { Should cardiovascular exercise be included } \\
\text { in lumbar fusion postop rehabilitation? }\end{array}$ & $\begin{array}{l}\text { Cardiovascular exercise is recommended to be included in lumbar fusion } \\
\text { postop rehabilitation programs to positively impact long-term health }\end{array}$ & B \\
\hline $\begin{array}{l}\text { Soft-tissue mobiliza- } \\
\text { tion }\end{array}$ & $\begin{array}{l}\text { Should soft-tissue mobilization be included } \\
\text { in lumbar fusion postop rehabilitation? }\end{array}$ & $\begin{array}{l}\text { There is insufficient evidence to make an argument for or against soft- } \\
\text { tissue mobilization's inclusion in lumbar fusion postop rehabilitation } \\
\text { programs }\end{array}$ & I \\
\hline Nerve mobilization & $\begin{array}{l}\text { Should nerve mobilization be included in } \\
\text { lumbar fusion postop rehabilitation? }\end{array}$ & $\begin{array}{l}\text { There is insufficient evidence to make an argument for or against } \\
\text { nerve mobilization's inclusion in lumbar fusion postop rehabilitation } \\
\text { programs }\end{array}$ & I \\
\hline $\begin{array}{l}\text { Motor control \& } \\
\text { strengthening }\end{array}$ & $\begin{array}{l}\text { Should motor control \& strengthening } \\
\text { exercises be included in lumbar fusion } \\
\text { postop rehabilitation? }\end{array}$ & $\begin{array}{l}\text { Neutral spine control exercises are recommended to be considered } \\
\text { as part of postop fusion rehabilitation to increase core strength \& } \\
\text { improve disability scores }\end{array}$ & $B$ \\
\hline Joint mobilization & $\begin{array}{l}\text { Should joint mobilization be included in } \\
\text { lumbar fusion postop rehabilitation? }\end{array}$ & $\begin{array}{l}\text { There is insufficient evidence to make an argument for or against } \\
\text { joint mobilization's inclusion in lumbar fusion postop rehabilitation } \\
\text { programs }\end{array}$ & 1 \\
\hline Patient education & $\begin{array}{l}\text { Should patient education be included in } \\
\text { lumbar fusion postop rehabilitation? }\end{array}$ & $\begin{array}{l}\text { Patient education is recommended as part of both pre- \& postop fusion } \\
\text { rehabilitation to facilitate clear communication btwn patients \& care } \\
\text { providers, to prepare patients for the postop rehabilitation regimen, \& } \\
\text { to improve outcomes while decreasing pain, complications, \& LOS }\end{array}$ & A \\
\hline $\begin{array}{l}\text { Timing \& duration of } \\
\text { postfusion rehabili- } \\
\text { tation }\end{array}$ & $\begin{array}{l}\text { What is the optimal timing \& duration of } \\
\text { lumbar fusion postop rehabilitation? }\end{array}$ & $\begin{array}{l}\text { Postop fusion rehabilitation is recommended to begin immediately, \& to } \\
\text { include education \& a walking program }\end{array}$ & $B$ \\
\hline $\begin{array}{l}\text { Need for rehabilitation } \\
\text { relative to surgery- } \\
\text { related morbidity }\end{array}$ & $\begin{array}{l}\text { How does the magnitude of surgery relate } \\
\text { to postop rehabilitation needs? }\end{array}$ & $\begin{array}{l}\text { Postop fusion rehabilitation is recommended after both minimally inva- } \\
\text { sive \& open lumbar fusion surgeries }\end{array}$ & C \\
\hline $\begin{array}{l}\text { Rehabilitation's } \\
\text { relationship to } \\
\text { outcomes }\end{array}$ & $\begin{array}{l}\text { What is the impact of postop rehabilitation } \\
\text { on treatment outcomes? }\end{array}$ & $\begin{array}{l}\text { Postop rehabilitation is recommended after lumbar fusion to improve } \\
\text { function \& pain in the months after surgery, \& to allow return to work }\end{array}$ & C \\
\hline $\begin{array}{l}\text { Psychosocial consid- } \\
\text { erations }\end{array}$ & $\begin{array}{l}\text { How do psychosocial diagnoses or support } \\
\text { systems impact clinical outcomes? }\end{array}$ & $\begin{array}{l}\text { Preop psychological testing prior to lumbar fusion \& postop psycho- } \\
\text { logical coping techniques in rehabilitation should be considered to } \\
\text { optimize outcomes }\end{array}$ & B \\
\hline
\end{tabular}

blood circulation, lengthening short or tight connective tissue, relaxing tense muscles, and soothing the nervous system. To date, no studies have assessed the effects of massage therapy on patients who have undergone lumbar fusion.

To some degree, the utility of these modalities may be extrapolated from other surgical milieux. Massage therapy administered postsurgically has been shown to decrease patients' pain and need for analgesics after colectomy and cesarean section. ${ }^{1,34,41}$ Patients who received massage therapy after cardiovascular surgery also had significant decreases in postsurgical pain as well as a reduction in anxiety and tension compared with those who received standard care. ${ }^{7,18}$

There is insufficient evidence to make an argument for or against soft-tissue mobilization's inclusion in lumbar fusion postoperative rehabilitation programs. Nevertheless, we recommend that care providers consider soft-tissue mobilization as a treatment option in postoperative fusion rehabilitation to provide a decrease in postsurgical pain and a reduction in anxiety and tension (Table 3 ). Soft-tissue mobilization may be most important for patients who are experiencing pain and swelling specifically around the incision site, as well as patients who are experiencing more anxiety or distress during their recovery.

\section{Nerve Mobilization}

Postoperative pain has occasionally been attributed to nerve root adherence to scar tissue around the decompressed thecal sac. Cadaver studies demonstrate nerve mobilization through the neuroforaminae. In the lower extremity, ultrasound measurements demonstrate 5.22 and $6.62 \mathrm{~mm}$ of longitudinal and lateral movement, respectively. ${ }^{22}$

The benefit of formal nerve mobilization procedures after lumbar fusion surgery remains contested, however. ${ }^{23}$ Scrimshaw and Maher reported a randomized controlled trial in which there was no difference in McGill Pain Questionnaire findings and the Quebec Disability Scale outcomes of lumbar surgery at 1 year between groups undergoing nerve mobilization and controls. ${ }^{61}$ On the other hand, a pilot study of healthy male soccer players showed improved ROM, as measured by the straight leg raise test in patients randomized to nerve mobilization..$^{14}$

Although there is insufficient evidence to make an argument for or against the inclusion of nerve mobilization 
in lumbar fusion postoperative rehabilitation programs, we believe that mobilization techniques are safe in the postlumbar fusion population. We recommend that care providers consider early nerve mobilization as a treatment option in postoperative fusion rehabilitation to improve ROM by decreasing postoperative nerve tension and decreasing scar tissue adherence to the nerve (Table 3).

\section{Motor Control and Strengthening}

Another common element in the studies analyzed is proper strengthening of trunk extensors and balancing of core musculature. ${ }^{8,64,65}$ Strengthening has long been a cornerstone of physical therapy. A number of studies have shown adverse effects of lumbar fusion on lumbar extensor function and density. ${ }^{38,39}$ Waschke and colleagues showed a correlation between inferior clinical outcome on 36Item Short Form Health Survey and visual analog scale tests if muscle atrophy due to denervation of the paraspinal muscles was present after posterior lumbar interbody fusion surgery. ${ }^{68}$ Given these new deficits, neuromuscular reeducation emphasizing efficient and effective movement is warranted to accommodate for healing muscles and new lumbar ROM restrictions. In 2004, Keller and others were able to demonstrate measured isokinetic strength gains of $184 \mathrm{Nm}$ and improved Biering-Sørensen positional holding times in patients randomized to an exercise program for disc degeneration or postlaminectomy syndrome. ${ }^{35}$

Cocontraction of abdominal and extensor muscles provides a splinting effect that may be protective to the spine. Although it is a controversial claim, some have argued that core strengthening may even decrease a patient's risk for adjacent-segment pathologies. ${ }^{67}$

Less controversially, fusion of one or more weightbearing segments of the spine will benefit from spinal motor control through functional, loading activities such as transfers, lifting, bending, and upright exercise. Proper neuromuscular reeducation for timing associated with muscle activation and increased intraabdominal pressures during these loaded movements should also be addressed. 21,65 Tarnanen and colleagues found "neutral spine control exercises" to be safe and effective during the rehabilitation of the postfusion population. ${ }^{65}$ These authors described each exercise and reported how electromyography findings support the exercise's effectiveness on activation of particular muscles, and they showed that measured increases in core strength correlated to lower Oswestry Disability Index (ODI) scores. ${ }^{64}$ Most of these exercises should be central to core stability efforts for patients with lumbar fusion, despite surgical intervention, and are commonly used by our coauthors from the rehabilitation departments. We recommend that care providers consider neutral spine control exercises as part of postoperative fusion rehabilitation to increase core strength and improve disability scores (Table 3).

\section{Joint Mobilization}

Joint mobilization and manipulation techniques have been shown to be effective in the treatment of low-back pain. ${ }^{33}$ Efficient movement requires optimization of not only lumbar ROM, but also those musculoskeletal units cranial and caudal to the spine. The available data support rehabilitation program strategies for thoracic spine and hip mobilization in maintaining proper posture, functional mobility, and decreasing stress on the healing fusion.

In 1999, Moffett et al. reported 1-year outcomes of a progressive exercise program in patients with low-back pain. ${ }^{49}$ One hundred eighty-seven patients were randomized into either CBT rehabilitation or the usual primary care management. The rehabilitation program included Oxford strengthening exercises consisting of a physical therapy evaluation followed by eight 1-hour group classes. A CBT component encouraged self-reliance and normal movement of the spine. At 1 year, significantly greater improvements in disability and back pain scores were reported. In that the rehabilitation patients missed far less work and used fewer health care resources, the authors concluded that this approach was more cost-effective.

Specifically, thoracic rotation training may assist patients' return to activities requiring seated rotation. ${ }^{47}$ It may also thereby decrease torsional stress on the healing lumbar spine and, perhaps, decrease nerve tension. One Italian study found that such manipulation was more beneficial than education and traditional therapy for pain and Roland-Morris scores. ${ }^{15}$ Although there is insufficient evidence to make an argument for or against joint mobilization's inclusion in lumbar fusion postoperative rehabilitation programs, we recommend that care providers consider thoracic spine and hip mobilization as a treatment option in postoperative fusion rehabilitation to maintain proper posture, increase functional mobility, and decrease stress on the healing fusion (Table 3).

\section{Patient Education}

The indications for lumbar surgery are clear in patients with progressive weakness or loss of function. However, when presented with chronic pain alone, patient selection can be daunting. Predicting the outcome of lumbar fusion surgery in the population with chronic low-back pain has proven difficult. ${ }^{70}$ Preoperative consultation with an experienced spine rehabilitation specialist to conduct biomechanical screening, improve compliance, and prepare the patient physically and mentally for surgical intervention could prove invaluable in these cases. Exercises such as low-impact aerobics have been shown to reduce pain in these patients. ${ }^{46}$

Patient education can be the cornerstone of rehabilitation, reducing anxiety and increasing patient empowerment, gratitude, and satisfaction. Building patient rapport is important for all members of the patient's care team and improves outcomes. ${ }^{20,25,60}$

Rosenberger et al. measured physician and patient preoperative expectations and compared them with postoperative outcomes in anterior cruciate ligament repairs. They found that physicians underestimated postoperative pain and overestimated function, yet were still better predictors of postoperative function and pain than were patients. This research calls for good preoperative communication between physicians and patients. ${ }^{59}$ The researchers have observed therapists' integral role in helping bridge this gap. Answering routine questions and helping prioritize more challenging questions for their surgeon can help patients feel more prepared. Setting up realistic expectations 
of how a surgery can be a part of the overall solution to chronic back pain may facilitate better outcomes. This scenario works best in the context of a multidisciplinary center where all providers stay in close communication and develop a level of trust for delivery of these services.

The education process begins preoperatively and involves several members of the care team. Ideally, each team member should give a consistent and cohesive message at each stage in the process. Preoperative education classes and written materials can be helpful in getting patients' questions and concerns addressed before surgery. Ideally, these sessions would include physical prehabilitation efforts to ready patients for the postoperative rehabilitation regimen before surgical pain and weakness are major factors. These efforts appear to improve outcomes while decreasing complications and LOS..$^{53}$ We recommend that care providers include patient education as part of both pre- and postoperative fusion rehabilitation to facilitate clear communication between patients and care providers, to ready patients for the postoperative rehabilitation regimen, and to improve outcomes while decreasing pain, complications, and LOS (Table 3).

\section{Timing and Duration of Postfusion Rehabilitation}

Few studies have examined the timing of initiation of postoperative rehabilitation. Oestergaard and colleagues randomized 2 groups of patients who underwent lumbar fusion to start rehabilitation at either 6 or 12 weeks postoperatively. The group starting at 12 weeks showed improved outcomes over the 6-week group in pain, activities of daily living, ODI, and Dallas Pain Questionnaire scores, even at 6-month follow-up. ${ }^{54-56}$ This protocol advocates a group setting of four 2-hour group sessions, which is modeled after the "Back Café" format proposed by Christensen et al. ${ }^{16}$ The exercises are outlined, but are not specifically detailed by individual exercise..$^{55}$

Duration of rehabilitation postfusion has several variables that should be considered. Patient comorbidities, preoperative deconditioning, age, disability, smoking, secondary orthopedic problems, psychosocial barriers (such as fear avoidance and/or depression), the patient's commitment and ability to exercise safely and independently, and pain control are factors that could require a patient to warrant closer monitoring from a rehabilitation specialist and necessitate starting therapy closer to the 2-month time frame to allow patient integration into the rehabilitation protocol. ${ }^{5,6,30,31,40,57} \mathrm{~A}$ "less is more" approach is probably best in a scenario in which a patient is progressing well. Likewise, fewer visits over a longer span of time allow for strength and motion progressions, as the fusion heals. Our current protocol under development has 3 tiers (accelerated, standard, and complex), accounting for patient variability.

We recommend that rehabilitation begin immediately, with education, nerve glides, and a walking program. This could be established during preoperative rehabilitation and reinforced in acute care settings, as indicated. Formal neutral spine rehabilitation should then begin at 2-3 months postoperatively to align with bony tissue healing time frames, progressing to mid- to end-range self-mobilization at 3-4 months, ${ }^{5-56}$ and carry a patient through the 6-month follow-up with the surgeon. The majority of these months may only require $1-2$ visits, after establishment of a home program. A successful program on an average patient who underwent 1- to 2-level lumbar fusion should be completed in fewer than 8 visits. We advocate immediate mobilization followed by formal, outpatient rehabilitation at 2-3 months postoperatively (Table 3 ). The primary high-LOE studies show 12 weeks as the optimal starting point, but these studies are limited in breadth. Although current research indicates 12 weeks as an optimal time frame on average, we recommend that an initial evaluation may be started up to 4 weeks early. This allows for an individualized aspect of the standard protocol, accounting for faster-healing patients, reviewing and correcting pre- and postoperative training, and for further education to assist therapy once the 12-week mark has been achieved.

\section{The Need for Rehabilitation Relative to Surgery-Related Morbidity}

We are not aware of any studies comparing the role of rehabilitation after 1-level versus multilevel lumbar fusion procedures; the impact of these surgeries on the extensor musculature is likely to be very different. These patients may also arrive at surgery with very different functional states. A similar assessment could be made comparing surgeries undertaken with a less invasive approach over more traditional, open surgeries.

Minimally invasive fusion approaches offer less tissue disruption than traditional open fusion procedures. Compared with patients who undergo open fusion, those who have the minimally invasive procedures may be able to start rehabilitation sooner, leading to a shorter LOS and earlier return to work. ${ }^{42}$

At this point, however, data for the influence of the extent of surgery on an appropriate rehabilitation protocol are not available. In those papers that more thoroughly examine rehabilitation after lumbar surgery, we find that the majority of them focus on microdiscectomies rather than lumbar fusions, with good evidence in favor of physical therapy for increased recovery. Although microdiscectomies and fusions are not identical and require different recovery time frames, there is enough correlation between the two that we can consider extrapolating from discectomy to fusion. ${ }^{66} \mathrm{We}$ recommend that care providers order postoperative fusion rehabilitation after both minimally invasive and open lumbar fusion surgeries (Table 3).

\section{Rehabilitation's Relationship to Outcomes}

Most studies find that early rehabilitation in the 3- to 6-month time frame increases early function and symptom control; however, ultimate function at 1-2 years continues to require higher-LOE research, because current studies do not show good evidence for or against therapy. ${ }^{28,32,45,48,52,54,63}$

In lumbar degenerative disease, long-term, randomized outcomes studies tend to show regression to the mean. That is, even when comparing operative versus nonoperative treatment strategies, longer-term follow-up suggests 
similar outcomes. ${ }^{10-12,24,29}$ Recently, Lurie and others published the 8-year results of the Spine Patient Outcomes Research Trial for lumbar spinal stenosis. Whereas outcomes remained stable in the observational cohort, the benefits of surgery diminished in the randomized group. ${ }^{43}$

Tarnanen et al.'s 2013 study does show a correlation between weak trunk extensor strength and increased disability as measured by the ODI, but it is limited by its shortterm follow-up. ${ }^{64}$ Oestergaard et al. demonstrate that the timing is important because beginning skilled therapy at 6 versus 12 weeks leads to a higher usage of health care services without a measurable increase in the overall quality of life. ${ }^{54}$ Yet they are unable to suggest an optimal initiation time frame at this point within their study's parameters. However, if rehabilitation at the 3-month time frame can show an earlier return to functional movement to enable regular work and activities of daily living in conjunction with improved psychological and psychosocial variables when compared with lack of skilled therapy, then skilled therapy services are warranted. Evaluating prehabilitation and outcome measures, Nielsen et al.'s study shows good evidence of improved outcomes and shortened hospital stay without increase in disability, pain, dissatisfaction, or complications after 1- to 2-level lumbar fusions. ${ }^{52}$

\section{Psychosocial Considerations}

In a 2010 review, Abbott et al. noted the interdependent nature of physical and psychological therapy during rehabilitation. ${ }^{2}$ Candidates for lumbar fusion surgery have probably had symptoms and compromised function for months to years. Over that time the episodic and/or chronic pain will have had an effect on these patients' psychological status, including fear/avoidance behavior, transitioning from an internal locus of control to an external locus of control, anxiety, catastrophizing, and depression.

Patients who undergo lumbar fusion have been shown to have significant fear of movement and (re)injury. Abbott et al. showed that approximately $80 \%$ of the study's patients who underwent lumbar spinal fusion had comorbid anxiety and/or depression. These patients also had lower health-related quality of life (HRQOL) and higher levels of pain. ${ }^{3}$ When neuroticism, anxiety, depression, fear/avoidance beliefs, catastrophizing, or kinesiophobia are present in a patient who undergoes lumbar fusion, a worse outcome is predicted. ${ }^{5,6,30,31,40}$ Smoking and off-work status for more than 13 weeks prior to surgery also predict a worse outcome. 6

Even psychologically healthy patients will endure psychological stress during the perioperative period. Stressors include the following: the financial costs of treatment, the potential loss of income while off from work, and the individual's compromised function, which may tax relationships and/or family dynamics.

Strategies used to address these issues are varied. Some studies have explored incorporating CBT, others include teaching relaxation and coping techniques along with rehabilitation, and still others have used patient-led group meetings along with a video of home exercises in replacement of traditional physical therapy. ${ }^{2,16,35,49,51}$ All of these have shown increased benefit to the patient in comparison with rehabilitation administered without these techniques, although there are no studies comparing one technique or approach against another.

Current data are inadequate to compare various forms of psychosocial support with others. Preoperative psychological testing has been shown to be effective in several studies. ${ }^{26,40,62}$ We recommend that care providers consider preoperative psychological testing prior to lumbar fusion; providers should consider including psychological coping techniques in postoperative rehabilitation.

\section{Discussion}

Postoperative rehabilitation means different things to different people. For some, it's a pamphlet and a recommendation that the patient walk. In European centers, a "Back Café" approach with psychosocial support in addition to exercise is often offered. Others recommend an aggressive program of isometric strengthening exercises.

We have analyzed the limited literature specifically pertaining to postfusion rehabilitation and have extrapolated recommendations, where necessary and appropriate, from the literature concerning rehabilitation after other spine procedures-most notably discectomy. Where highgrade evidence is not available we identified this deficit but made recommendations based on our group's extensive, multidisciplinary experience with these patients.

Based on our analysis of these studies and on our experience, we have listed a set of definitions for the components of rehabilitation that we propose should be addressed in planning postoperative rehabilitation for patients who undergo lumbar fusion. These are as follows: 1) cardiovascular exercise; 2) soft-tissue mobilization; 3) nerve mobilization; 4) motor control and strengthening; 5) joint mobilization; and 6) patient education.

We examined the optimal timing and duration of postfusion rehabilitation, and we advocate immediate mobilization followed by formal, outpatient rehabilitation at 2-3 months postoperatively. We also evaluated postfusion rehabilitation's relationship to the extent of surgery and whether it is known if postfusion rehabilitation improves outcome. Although there are no direct data addressing this concept, we recommend rehabilitation after fusion regardless of number of levels or degree of invasiveness of the operation. We also analyzed the importance of psychosocial considerations when planning both surgery and postfusion rehabilitation. When possible, psychological testing and teaching of coping strategies should be considered by care providers.

We graded recommendations very conservatively because many of the papers reviewed did not directly address postlumbar fusion rehabilitation. Even where there was insufficient evidence, we made recommendations in which we extrapolated from the evidence available and our clinical practices to the postfusion scenario.

Our review is chiefly limited by the data available. We have designed a protocol for postoperative rehabilitation and are studying this program prospectively. So far, we have not been able to identify any harm from the program in total or in any of its components. The relative benefits from the program or its constituent parts are the focus of 
our ongoing study. Additionally, we seek to identify those subgroups of patients with lumbar fusion who are most likely to benefit from formal postoperative rehabilitation, and to perform cost utility analyses.

\section{Conclusions}

Rehabilitation has long been a common feature in the postoperative management of patients with spinal fusion, but without a clear understanding by many providers of what that rehabilitation should include and why. Although most caregivers agree that most patients will benefit from this effort, the supporting data remain sparse. In this review we have provided a list of and have made evidencebased recommendations for components that should be included in postlumbar fusion rehabilitation. We have also discussed the optimal timing and duration, and we advocate immediate mobilization followed by formal, outpatient rehabilitation at 2-3 months postoperatively. At this point, although much additional research is required, we have begun to construct from the data an active, patientdriven rehabilitation protocol. This protocol is undergoing prospective study to examine its cost per quality-adjusted life year features and its impact on patient-reported function.

\section{References}

1. Abbaspoor Z, Akbari M, Najar S: Effect of foot and hand massage in post-cesarean section pain control: a randomized control trial. Pain Manag Nurs 15:132-136, 2014

2. Abbott AD, Tyni-Lenné R, Hedlund R: Early rehabilitation targeting cognition, behavior, and motor function after lumbar fusion: a randomized controlled trial. Spine (Phila Pa 1976) 35:848-857, 2010

3. Abbott AD, Tyni-Lenné R, Hedlund R: The influence of psychological factors on pre-operative levels of pain intensity, disability and health-related quality of life in lumbar spinal fusion surgery patients. Physiotherapy 96:213-221, 2010

4. Andersen T, Christensen FB, Egund N, Ernst C, Fruensgaard S, Østergaard J, et al: The effect of electrical stimulation on lumbar spinal fusion in older patients: a randomized, controlled, multi-center trial: part 2: fusion rates. Spine (Phila Pa 1976) 34:2248-2253, 2009

5. Archer KR, Motzny N, Abraham CM, Yaffe D, Seebach CL, Devin CJ, et al: Cognitive-behavioral-based physical therapy to improve surgical spine outcomes: a case series. Phys Ther 93:1130-1139, 2013

6. Archer KR, Seebach CL, Mathis SL, Riley LH III, Wegener ST: Early postoperative fear of movement predicts pain, disability, and physical health six months after spinal surgery for degenerative conditions. Spine J 14:759-767, 2014

7. Bauer BA, Cutshall SM, Wentworth LJ, Engen D, Messner PK, Wood CM, et al: Effect of massage therapy on pain, anxiety, and tension after cardiac surgery: a randomized study. Complement Ther Clin Pract 16:70-75, 2010

8. Biering-Sørensen F: Physical measurements as risk indicators for low-back trouble over a one-year period. Spine (Phila Pa 1976) 9:106-119, 1984

9. Brennan GP, Shultz BB, Hood RS, Zahniser JC, Johnson SC, Gerber AH: The effects of aerobic exercise after lumbar microdiscectomy. Spine (Phila Pa 1976) 19:735-739, 1994

10. Brox JI, Nygaard ØP, Holm I, Keller A, Ingebrigtsen T, Reikerås O: Four-year follow-up of surgical versus nonsurgical therapy for chronic low back pain. Ann Rheum Dis 69:1643-1648, 2010

11. Brox JI, Reikerås O, Nygaard $\emptyset$, Sørensen R, Indahl A, Holm
I, et al: Lumbar instrumented fusion compared with cognitive intervention and exercises in patients with chronic back pain after previous surgery for disc herniation: a prospective randomized controlled study. Pain 122:145-155, 2006

12. Brox JI, Sørensen R, Friis A, Nygaard Ø, Indahl A, Keller A, et al: Randomized clinical trial of lumbar instrumented fusion and cognitive intervention and exercises in patients with chronic low back pain and disc degeneration. Spine (Phila Pa 1976) 28:1913-1921, 2003

13. Brox JI, Storheim K, Holm I, Friis A, Reikerås O: Disability, pain, psychological factors and physical performance in healthy controls, patients with sub-acute and chronic low back pain: a case-control study. J Rehabil Med 37:95-99, 2005

14. Castellote-Caballero Y, Valenza MC, Martín-Martín L, Cabrera-Martos I, Puentedura EJ, Fernández-de-Las-Peñas $\mathrm{C}$ : Effects of a neurodynamic sliding technique on hamstring flexibility in healthy male soccer players. A pilot study. Phys Ther Sport 14:156-162, 2013

15. Cecchi F, Molino-Lova R, Chiti M, Pasquini G, Paperini A, Conti AA, et al: Spinal manipulation compared with back school and with individually delivered physiotherapy for the treatment of chronic low back pain: a randomized trial with one-year follow-up. Clin Rehabil 24:26-36, 2010

16. Christensen FB, Laurberg I, Bünger CE: Importance of the back-café concept to rehabilitation after lumbar spinal fusion: a randomized clinical study with a 2-year follow-up. Spine (Phila Pa 1976) 28:2561-2569, 2003

17. Cowan JA Jr, Dimick JB, Wainess R, Upchurch GR Jr, Chandler WF, La Marca F: Changes in the utilization of spinal fusion in the United States. Neurosurgery 59:15-20, 2006

18. Cutshall SM, Wentworth LJ, Engen D, Sundt TM, Kelly RF, Bauer BA: Effect of massage therapy on pain, anxiety, and tension in cardiac surgical patients: a pilot study. Complement Ther Clin Pract 16:92-95, 2010

19. Deyo RA, Mirza SK: The case for restraint in spinal surgery: does quality management have a role to play? Eur Spine J 18 (Suppl 3):331-337, 2009

20. Egbert LD, Battit GE, Welch CE, Bartlett MK: Reduction of postoperative pain by encouragement and instruction of patients. A study of doctor-patient rapport. N Engl J Med 270:825-827, 1964

21. El Ouaaid Z, Shirazi-Adl A, Plamondon A, Larivière C: Trunk strength, muscle activity and spinal loads in maximum isometric flexion and extension exertions: a combined in vivo-computational study. J Biomech 46:2228-2235, 2013

22. Ellis R, Hing W, Dilley A, McNair P: Reliability of measuring sciatic and tibial nerve movement with diagnostic ultrasound during a neural mobilisation technique. Ultrasound Med Biol 34:1209-1216, 2008

23. Ellis RF, Hing WA: Neural mobilization: a systematic review of randomized controlled trials with an analysis of therapeutic efficacy. J Manual Manip Ther 16:8-22, 2008

24. Fairbank J, Frost H, Wilson-MacDonald J, Yu LM, Barker K, Collins R: Randomised controlled trial to compare surgical stabilisation of the lumbar spine with an intensive rehabilitation programme for patients with chronic low back pain: the MRC spine stabilisation trial. BMJ 330:1233, 2005

25. Farin E, Gramm L, Schmidt E: The patient-physician relationship in patients with chronic low back pain as a predictor of outcomes after rehabilitation. J Behav Med 36:246-258, 2013

26. Flanigan DC, Everhart JS, Glassman AH: Psychological factors affecting rehabilitation and outcomes following elective orthopaedic surgery. J Am Acad Orthop Surg 23:563-570, 2015

27. Fritz JM, Lurie JD, Zhao W, Whitman JM, Delitto A, Brennan GP, et al: Associations between physical therapy and long-term outcomes for individuals with lumbar spinal stenosis in the SPORT study. Spine J 14:1611-1621, 2014 
28. Froholdt A, Holm I, Keller A, Gunderson RB, Reikeraas O, Brox JI: No difference in long-term trunk muscle strength, cross-sectional area, and density in patients with chronic low back pain 7 to 11 years after lumbar fusion versus cognitive intervention and exercises. Spine J 11:718-725, 2011

29. Froholdt A, Reikeraas O, Holm I, Keller A, Brox JI: No difference in 9-year outcome in CLBP patients randomized to lumbar fusion versus cognitive intervention and exercises. Eur Spine J 21:2531-2538, 2012

30. Hägg O, Fritzell P, Ekselius L, Nordwall A: Predictors of outcome in fusion surgery for chronic low back pain. A report from the Swedish Lumbar Spine Study. Eur Spine J 12:22-33, 2003

31. Hägg O, Fritzell P, Nordwall A: The clinical importance of changes in outcome scores after treatment for chronic low back pain. Eur Spine J 12:12-20, 2003

32. Häkkinen A, Ylinen J, Kautiainen H, Tarvainen U, Kiviranta I: Effects of home strength training and stretching versus stretching alone after lumbar disk surgery: a randomized study with a 1-year follow-up. Arch Phys Med Rehabil 86:865-870, 2005

33. Hidalgo B, Detrembleur C, Hall T, Mahaudens P, Nielens $\mathrm{H}$ : The efficacy of manual therapy and exercise for different stages of non-specific low back pain: an update of systematic reviews. J Manual Manip Ther 22:59-74, 2014

34. Kaiser MG, Eck JC, Groff MW, Watters WC III, Dailey AT, Resnick DK, et al: Guideline update for the performance of fusion procedures for degenerative disease of the lumbar spine. Part 1: introduction and methodology. J Neurosurg Spine 21:2-6, 2014

35. Keller A, Brox JI, Gunderson R, Holm I, Friis A, Reikerås $\mathrm{O}$ : Trunk muscle strength, cross-sectional area, and density in patients with chronic low back pain randomized to lumbar fusion or cognitive intervention and exercises. Spine (Phila Pa 1976) 29:3-8, 2004

36. Kepler CK, Vaccaro AR, Hilibrand AS, Anderson DG, Rihn JA, Albert TJ, et al: National trends in the use of fusion techniques to treat degenerative spondylolisthesis. Spine (Phila Pa 1976) 39:1584-1589, 2014

37. Kjellby-Wendt G, Styf J, Carlsson SG: Early active rehabilitation after surgery for lumbar disc herniation: a prospective, randomized study of psychometric assessment in 50 patients. Acta Orthop Scand 72:518-524, 2001

38. Kramer M, Katzmaier P, Eisele R, Ebert V, Kinzl L, Hartwig E: Surface electromyography-verified muscular damage associated with the open dorsal approach to the lumbar spine. Eur Spine J 10:414-420, 2001

39. Kramer M, Völker HU, Weikert E, Katzmaier P, Sterk J, Willy C, et al: Simultaneous measurement of intramuscular pressure and surface electromyography of the multifidus muscle. Eur Spine J 13:530-536, 2004

40. LaCaille RA, DeBerard MS, Masters KS, Colledge AL, Bacon W: Presurgical biopsychosocial factors predict multidimensional patient: outcomes of interbody cage lumbar fusion. Spine J 5:71-78, 2005

41. Le Blanc-Louvry I, Costaglioli B, Boulon C, Leroi AM, Ducrotte P: Does mechanical massage of the abdominal wall after colectomy reduce postoperative pain and shorten the duration of ileus? Results of a randomized study. J Gastrointest Surg 6:43-49, 2002

42. Lee KH, Yue WM, Yeo W, Soeharno H, Tan SB: Clinical and radiological outcomes of open versus minimally invasive transforaminal lumbar interbody fusion. Eur Spine J 21:2265-2270, 2012

43. Lurie JD, Tosteson TD, Tosteson A, Abdu WA, Zhao W, Morgan TS, et al: Long-term outcomes of lumbar spinal stenosis: eight-year results of the Spine Patient Outcomes Research Trial (SPORT). Spine (Phila Pa 1976) 40:63-76, 2015

44. Mannion AF, Brox JI, Fairbank JC: Comparison of spinal fusion and nonoperative treatment in patients with chronic low back pain: long-term follow-up of three randomized controlled trials. Spine J 13:1438-1448, 2013

45. Mannion AF, Denzler R, Dvorak J, Müntener M, Grob D: A randomised controlled trial of post-operative rehabilitation after surgical decompression of the lumbar spine. Eur Spine J 16:1101-1117, 2007

46. Mannion AF, Müntener M, Taimela S, Dvorak J: Comparison of three active therapies for chronic low back pain: results of a randomized clinical trial with one-year follow-up. Rheumatology (Oxford) 40:772-778, 2001

47. Millan M, Leboeuf-Yde C, Budgell B, Descarreaux M, Amorim MA: The effect of spinal manipulative therapy on spinal range of motion: a systematic literature review. Chiropr Man Therap 20:23, 2012

48. Mirza SK, Deyo RA: Systematic review of randomized trials comparing lumbar fusion surgery to nonoperative care for treatment of chronic back pain. Spine (Phila Pa 1976) 32:816-823, 2007

49. Moffett JK, Torgerson D, Bell-Syer S, Jackson D, LlewlynPhillips H, Farrin A, et al: Randomised controlled trial of exercise for low back pain: clinical outcomes, costs, and preferences. BMJ 319:279-283, 1999

50. Moher D, Liberati A, Tetzlaff J, Altman DG: Preferred reporting items for systematic reviews and meta-analyses: the PRISMA statement. Int J Surg 8:336-341, 2010

51. Monticone M, Ferrante S, Teli M, Rocca B, Foti C, Lovi A, et al: Management of catastrophising and kinesiophobia improves rehabilitation after fusion for lumbar spondylolisthesis and stenosis. A randomised controlled trial. Eur Spine J 23:87-95, 2014

52. Nielsen PR, Andreasen J, Asmussen M, Tønnesen H: Costs and quality of life for prehabilitation and early rehabilitation after surgery of the lumbar spine. BMC Health Serv Res 8:209, 2008

53. Nielsen PR, Jørgensen LD, Dahl B, Pedersen T, Tønnesen H: Prehabilitation and early rehabilitation after spinal surgery: randomized clinical trial. Clin Rehabil 24:137-148, 2010

54. Oestergaard LG, Christensen FB, Nielsen CV, Bünger CE, Fruensgaard S, Sogaard R: Early versus late initiation of rehabilitation after lumbar spinal fusion: economic evaluation alongside a randomized controlled trial. Spine (Phila Pa 1976) 38:1979-1985, 2013

55. Oestergaard LG, Nielsen CV, Bünger CE, Sogaard R, Fruensgaard S, Helmig P, et al: The effect of early initiation of rehabilitation after lumbar spinal fusion: a randomized clinical study. Spine (Phila Pa 1976) 37:1803-1809, 2012

56. Oestergaard LG, Nielsen CV, Bünger CE, Svidt K, Christensen FB: The effect of timing of rehabilitation on physical performance after lumbar spinal fusion: a randomized clinical study. Eur Spine J 22:1884-1890, 2013

57. Ostelo RW, de Vet HC, Waddell G, Kerckhoffs MR, Leffers $\mathrm{P}$, van Tulder M: Rehabilitation following first-time lumbar disc surgery: a systematic review within the framework of the Cochrane collaboration. Spine (Phila Pa 1976) 28:209-218, 2003

58. Poitras S, Rossignol M, Dionne C, Tousignant M, Truchon M, Arsenault B, et al: An interdisciplinary clinical practice model for the management of low-back pain in primary care: the CLIP project. BMC Musculoskelet Disord 9:54, 2008

59. Rosenberger PH, Jokl P, Cameron A, Ickovics JR: Shared decision making, preoperative expectations, and postoperative reality: differences in physician and patient predictions and ratings of knee surgery outcomes. Arthroscopy 21:562-569, 2005

60. Sawyer MW: The role of the physical therapist before and after lumbar spine surgery. Orthop Clin North Am 14:649659,1983

61. Scrimshaw SV, Maher CG: Randomized controlled trial of 
neural mobilization after spinal surgery. Spine (Phila Pa 1976) 26:2647-2652, 2001

62. Skolasky RL, Mackenzie EJ, Wegener ST, Riley LH III: Patient activation and functional recovery in persons undergoing spine surgery. J Bone Joint Surg Am 93:1665-1671, 2011

63. Tarnanen S, Neva MH, Dekker J, Häkkinen K, Vihtonen K, Pekkanen L, et al: Randomized controlled trial of postoperative exercise rehabilitation program after lumbar spine fusion: study protocol. BMC Musculoskelet Disord 13:123, 2012

64. Tarnanen S, Neva MH, Kautiainen H, Ylinen J, Pekkanen L, Kaistila T, et al: The early changes in trunk muscle strength and disability following lumbar spine fusion. Disabil Rehabil 35:134-139, 2013

65. Tarnanen SP, Neva MH, Häkkinen K, Kankaanpää M, Ylinen J, Kraemer WJ, et al: Neutral spine control exercises in rehabilitation after lumbar spine fusion. J Strength Cond Res 28:2018-2025, 2014

66. Timm KE: A randomized-control study of active and passive treatments for chronic low back pain following L5 laminectomy. J Orthop Sports Phys Ther 20:276-286, 1994

67. Virk SS, Niedermeier S, Yu E, Khan SN: Adjacent segment disease. Orthopedics 37:547-555, 2014

68. Waschke A, Hartmann C, Walter J, Dünisch P, Wahnschaff F, Kalff R, et al: Denervation and atrophy of paraspinal muscles after open lumbar interbody fusion is associated with clinical outcome-electromyographic and CT-volumetric investigation of 30 patients. Acta Neurochir (Wien) 156:235-244, 2014

69. Weinstein JN, Lurie JD, Tosteson TD, Zhao W, Blood EA, Tosteson AN, et al: Surgical compared with nonoperative treatment for lumbar degenerative spondylolisthesis. Fouryear results in the Spine Patient Outcomes Research Trial (SPORT) randomized and observational cohorts. J Bone Joint Surg Am 91:1295-1304, 2009

70. Willems P: Decision making in surgical treatment of chronic low back pain: the performance of prognostic tests to select patients for lumbar spinal fusion. Acta Orthop Suppl 84:135,2013

\section{Disclosures}

The authors report no conflict of interest concerning the materials or methods used in this study or the findings specified in this paper.

\section{Author Contributions}

Conception and design: Truumees, Madera, Brady, Deily, McGinty, Singh, Tipton. Acquisition of data: Truumees, Madera, Brady, Deily, McGinty, Singh. Analysis and interpretation of data: all authors. Drafting the article: Madera, Brady, Deily, McGinty, Moroz, Singh, Tipton. Critically revising the article: all authors. Reviewed submitted version of manuscript: all authors. Approved the final version of the manuscript on behalf of all authors:

Truumees. Administrative/technical/material support: Truumees, Singh. Study supervision: Truumees.

\section{Supplemental Information \\ Online-Only Content}

Supplemental material is available with the online version of the article.

Appendix. https://thejns.org/doi/suppl/10.3171/2016.10. SPINE16627.

\section{Correspondence}

Eeric Truumees, Seton Spine and Scoliosis Center, 1600 West 38th St., Ste. 200, Austin, TX 78731-6400.email: etruumees@ seton.org. 